\title{
Associação de Vibrio cholerae com o zooplâncton de águas estuárias da Baía de São Marcos/São Luis - MA, Brasil
}

\author{
Association between Vibrio cholerae and zooplankton of estuaries \\ of São Marcos Bay/São Luis - MA, Brazil \\ Eloisa da Graça do Rosario Gonçalves ${ }^{1}$, Maria José Saraiva Lopes², \\ Eurípedes Gomes de Oliveira ${ }^{1}$ e Ernesto Hofer ${ }^{3}$
}

\begin{abstract}
RESUMO
Foi investigado, no período de outubro de 1997 a outubro de 1998, a possível associação de Vibrio cholerae com o zooplâncton dos estuários dos rios Anil e Bacanga, em São Luis - MA, Brasil, a presença da forma viável, mas não cultivável de Vibrio cholerae $\mathrm{O1}$ ea correlação entre pH, salinidade e temperatura da água com a sobrevivência da bactéria. Amostras de zooplâncton foram coletadas em dois pontos fixos em cada estuário. 0 método clássico de isolamento e imunofluorescência direta foram empregados na detecção da bactéria. Nas 52 amostras obtidas de zooplâncton houve predomínio de Copepodes. 0 cultivo permitiu a obtenção de 55 isolados de Vibrio cholerae não 01. Os sorogrupos 01 e 0139 foram demonstrados, respectivamente em 37 ( 71,1\%) e 17 ( 32,7\%) na imunofluorescência. Formas viáveis, mas não cultiváveis de Vibrio cholerae 01 foram detectadas em 70,8\% das amostras estudadas. Correlação significativa foi constatada entre salinidade e pH da água e isolamento de Vibrio cholerae.
\end{abstract}

Palavras-chaves: Vibrio cholerae. Ecologia. Zooplâncton. Baía de São Marcos.

\section{ABSTRACT}

This study was carried from October 1997 to October 1998 with the purpose of investigating the link between the species Vibrio cholerae and zooplankton in the estuaries of rivers Anil and Bacanga in São Luis, Maranhão. Research of viable but non culturable forms of Vibrio cholerae 01, and analyze the correlation between $\mathrm{pH}$ values, salinity and water temperature with the presence of bacteria in zooplankton samples. The traditional method of cultivation and fluorescent antibody technique were applied to detect the bacteria. A total of 52 samples of zooplankton were collected. There was a predominance of Copepoda. The culture enabled 55 isolates of Vibrio cholerae non-01. The serogroups 01 and 0139 were identified in 37 (71.1\%) and 17 (32.7\%) samples respectively by the fluorescence. Viable but non culturable forms of Vibrio cholerae were detected in $70.8 \%$ of the samples studied. A significant correlation was established between salinity and the water's pH value and Vibrio cholerae.

Key-words: Vibrio cholerae. Ecology. Zooplankton. São Marcos Bay.

0 padrão epidemiológico da cólera tem passado por mudanças significativas nas últimas décadas em decorrência do processo de endemização, em que exacerbações da doença são intercaladas por períodos silenciosos, seguindo um padrão sazonal ${ }^{25}$. Vários mecanismos foram propostos para explicar a sobrevivência do bacilo nos períodos interepidêmicos, sendo as evidências epidemiológicas e laboratoriais mais consistentes com a existência de reservatórios ambientais. Esta hipótese fora defendida por Robert Koch, em 1884, após isolar o vibrião de água de um tanque em Calcutá20 ${ }^{20}$. Minuciosos trabalhos de revisão registram estudos em vários países nas primeiras décadas do século XX, demonstrando a presença do Vibrio em diferentes ambientes aquáticos ${ }^{9}{ }^{29}$.

\footnotetext{
1. Departamento de Patologia da Universidade Federal do Maranhão, São Luis, MA. 2. Departamento de Oceanografia da Universidade Federal do Maranhão, São Luis, MA. 3. Laboratório de Zoonoses Bacterianas da Fundação Instituto Oswaldo Cruz, Rio de janeiro, RJ.

Apoio financeiro: CAPES

Endereço para correspondência: Dra. Eloisa da Graça do Rosario Gonçalves. Depto de Patologia/UFMA. Praça Madre Deus 2, Térreo, Bairro Madre Deus, 65025-560 São Luis, MA.

Tel: $5598221-0270$

e-mail: regionalsbmt@elo.com.br

Recebido para publicação em 16/10/2003

Aceito em 19/05/2004
} 
№ Brasil, foram isolados Vibrio cholerae 01 e não-01 em afluentes de estações de tratamento de esgotos, na década de $70 \mathrm{e}$ início dos anos $80^{14} 23$. Peixes, ostras, camarões e caranguejos constituem fontes de infecção, sendo identificados como causa de epidemias ou casos isolados de cólera nos Estados Unidos, Itália, Portugal e Austrália, entre outros países 9 . Estudos revelam, ainda, a associação de V. cholerae 01 com plantas aquáticas e fitoplâncton ${ }^{17}{ }^{18}$.

Copépodes marinhos albergam uma flora bacteriana composta por membros da família Vibrionacea ${ }^{32}$, 0 que foi confirmado por microscopia eletrônica ${ }^{15}$. A interação com 0 zooplâncton parece ser decisiva na sobrevivência ambiental do V. cholerae, conforme tem sido observado em microecossistemas experimentais ${ }^{2} 15$.

Fatores ambientais, destacando-se pH, temperatura, salinidade e concentração de nutrientes exercem importante influência nessa interação, sendo $0 \mathrm{~V}$. cholerae mais ativo em condições que se aproximam das características naturais dos estuários ${ }^{16} 2428$. Nessas condições, contudo, 0 cultivo de V. cholerae 01 pelo método classicamente utilizado, ao contrário de $\mathrm{V}$. cholerae não 01, é bastante difícil nos períodos interepidêmicos.

0 emprego da imunofluorescência indireta para a demonstração da bactéria em amostras de água e, posteriormente, a associação com a contagem direta de células viáveis, permitiram a detecção de formas viáveis, mas não cultiváveis do vibrião colérico em ambientes aquáticos ${ }^{8}{ }^{33}$. Anticorpos monoclonais contra a fração " $\mathrm{A}$ " do antígeno somático do V. cholerae 01, assim como contra 0 determinante antigênico do lipopolissacarídeo do sorogrupo 0139, aliados à técnica direta de coloração, elevaram a sensibilidade, especificidade e valor preditivo positivo enegativo do método a $100 \%$, quando testado no campo ${ }^{11}{ }^{12}$.

0 Estado do Maranhão foi atingido pela epidemia de cólera que ocorreu no continente sulamericano a partir de 1991, havendo registro da doença na capital, São Luis, de 1992 a 1995. 0 município localiza-se às margens da Baía de São Marcos, onde daságuam as várias bacias hidrográficas do estado ${ }^{10}$. Com nascente no interior da Ilha de São Luis, destacam-se os rios Bacanga e Anil (extensão de $9.500 \mathrm{~m}$ e $13.800 \mathrm{~m}$, respectivamente), os quais percorrem áreas urbanas e com os quais as populações ribeirinhas mantêm estreita relação. 0 desenvolvimento deste trabalho levou em conta estes dados, tendo 0 objetivo de investigar a presença de V. cholerae em associação com a rica fauna zooplanctônica da região.

\section{MATERIAL E MÉTODOS}

A área de estudo compreende os estuários dos rios Anil e Bacanga que percorrem a Ilha de São Luis e deságuam na Baía de São Marcos, tendo sido definidas 2 estações de amostragem (1 e 2) , em cada estuário. 0 estuário do rio Anil recebe influência direta de águas marinhas costeiras, enquanto 0 estuário do rio Bacanga encontra-se limitado, em parte, por uma barragem artificial e por comportas que são abertas a intervalos trimestrais. As coletas de zooplâncton foram feitas em intervalos mensais, de outubro de 1997 a outubro de 1998, empregando-se rede de plâncton, confeccionada com malha de $65 \mathrm{~mm}$ de abertura, em arrastos horizontais, subsuperficiais, durante 5 minutos. 0 material foi dividido em 2 partes: uma para 0 estudo bacteriológico, mantido em frascos estéreis, à temperatura ambiente; outra, em frascos contendo solução de formaldeído a 4\%, neutralizado com borato de sódio, destinada à identificação do zooplâncton. Medidas de pH, temperatura e salinidade da água foram tomadas in loco, utilizandose salinometer/termômetro Beckman e pHmeter Hanna HI 9025C.

A identificação dos organismos zooplanctônicos foi feita seguindo critérios morfológicos clássicos estabelecidos ${ }^{3450}$.

0 material destinado ao cultivo bacteriano foi centrifugado a 3.000rpm, durante 10 minutos, sendo feitas lavagens do sedimento por 3 vezes com água destilada. Tanto 0 sedimento final, quanto 0 sobrenadante foram semeados em $10 \mathrm{ml}$ deágua peptonada contendo $1 \%$ de $\mathrm{NaCl}$. Após incubação a $37^{\circ} \mathrm{C}$ por 6 horas, 0 crescimento foi semeado em AgarTCBS. De 3 a 5 colônias ( sacarose positivas e negativas) foram submetidas a estudo bioquímico. Todas as amostras não halofílicas, compatíveis bioquimicamente com a espécie V. cholerae foram submetidas à soroaglutinação, empregandose antígenos somáticos dos sorogrupos 01 e 0139 e dos sorotipos Inaba e Ogawa, produzidos no Laboratório Nacional de Referência de Cólera, IOC/FIOCRUZ, Rio de Janeiro.

Para a realização da imunofluorescência direta foram empregados anticorpos monoclonais contra os sorogrupos $01 \mathrm{e}$ 0139 ( New Horizons Diagnostics Corp. Columbia, MD) , marcados com fluoresceína, sob forma liofilizada e reconstituída com $1 \mathrm{ml}$ de água destilada antes do uso. Amostras de zooplâncton conservadas em formalina foram centrifugadas, confeccionadose esfregaços com o sedimento, em lâminas de vidro com poços circulares. Controles positivos e negativos foram incluídos em todos os testes. Cada poço foi coberto com 10ml do anticorpo, sendo as lâminas incubadas em câmara úmida, à temperatura de $37^{\circ} \mathrm{C}$, durante 30 minutos e, em seguida, lavadas com salina tamponada, em dois ciclos de 10 minutos. A leitura foi feita em microscópio de fluorescência, com comprimento de onda BP 450-490mm e lâmpada $\mathrm{HBO}$ 50, em aumento de 400 vezes.

Vinte e quatro amostras de zooplâncton recém coletadas e não fixadas com formalina, recolhidas no período de maio a outubro de 1998 foram utilizadas para a pesquisa das formas viáveis, mas não cultiváveis, conforme técnica descrita por Brayton e cols ${ }^{6}$.

\section{RESULTAD0S}

Foram obtidas 52 amostras de zooplâncton, identificandose grande variedade de organismos. A distribuição nos diferentes meses de coleta revela o predomínio de Copepoda ( concentração superior a 50\% em relação aos outros grupos) em 98,1\% das amostras provenientes do Rio Anil e em 86,5\% das amostras do Rio Bacanga. As Figuras 1 e 2 mostram a variedade de organismos identificados nos estuários.

Năo houve isolamento de V. cholerae 01 e 0139 no cultivo em TCBS. 0 método permitiu, no entanto, a obtenção de 55 isolados de $\mathrm{V}$. cholerae não 01 a partir de 14 amostras coletadas de dezembro de 1997 a setembro de 1998. Foram identificados os tipos bioquímicos I, II e III de Heiberg ${ }^{13}$, havendo predomínio do tipo II (Tabela 1). 


\begin{tabular}{||ll||}
\hline HOLOPLÂNCTON & Tintinnida \\
Copeepoda (Calanoida) & Favella ehrenbergi Claparide y \\
Eucalanus pileatus Giesbrecht, 1888 & Lichman Jorgensen, 1924 \\
Acartia lilljeborgi Giesbrecht, 1892 & Tintinnopsis sp \\
Centropages velificatus Dana, 1849 & Decapoda \\
Centropages brachiatus Dana, 1849 & Lucifer faxoni Borradaille, 1915 \\
Labidocera fluviatilis E. Dahl, 1894 & \\
Paracalanus crassirostris E. Dahl, 1894 & Ostrocoda \\
Paracalanus aculeatus Giesbrecht, 1888 & Hydromedusae \\
Pseudodiaptomus acutus E. Dahl, 1894 & \\
Temora turbinata Wright, 1836 & Rotifera \\
Temora stylifera Dana, 1848 & Brachionus plicatilis \\
Pontelopsis vilosae Brady, 1883 & 0 F Muller, 1786 \\
Pontelopsis sp & Nematoda \\
Eucalanus sewelli Dana, 1849 & Isopoda \\
Calanopia americana F. Dahl, 1894 & Amphipoda \\
Pontelina plumata L Oliveira, 1947 & \\
Clausocalanus furcatus Brady, 1883 & Chaetognatha \\
& Sagitta sp \\
Copepoda (Cyclopoida) & Sagitta enflata \\
Oithona hebes Giesbrecht, 1891 & \\
Oithona oswaldocruzi L Oliveira, 1947 & Appendicularia \\
Oithona nana Giesbrecht, 1892 & Oikopleura dioica \\
Oithona simplex Claus, 1863 & \\
Hemicyclops thalassius Vervoort y Ramires, 1966 & MEROPLANCTON \\
Mesocyclops sp & Gasrropoda (larva) \\
Cyclops sp & Bivalvia (veliger) \\
Termocyclops sp & Polychaeta (trocofora) \\
Apocyclops panamensis Marsh, 1982 & Brachyura (zocas) \\
Corycaeus giesbrechti E. Dahl, 1894 & Cirripedia (cypris e nauplii) \\
Oncaea media Giesbrecht, 1891 & Copepoda (nauplii) \\
Oncaea sp & Porcelanidae (larva) \\
Copepoda Harpaticoida & Pennacidae (larva) \\
Euterpina acutifrons Dana, 1892 & Echinodermata (larva) \\
Atheylla sp & Insecta (larva) \\
Ergasilus sp & Pisces ( ovos) \\
Harpaticoides sp & \\
\hline
\end{tabular}

Figura 1 - Zooplâncton encontrado no estuário do Rio Anil / São Luis - MA( outubro de 1997 a outubro de 1998)

\begin{tabular}{|ll|}
\hline HOLOPLÂNCTON & Tintinnida \\
Copeepoda (Calanoida) & Favella ehrenbergi Claparide y \\
Eucalanus pileatus Giesbrecht, 1888 & Lichman Jorgensen, 1924 \\
Acartia lilljeborgi Giesbrecht, 1892 & Tintinnopsis sp \\
Centropages velificatus Dana, 1849 & Amphorelopsis sp \\
Eucalanus pileatus Giesbrecht, 1882 & Condonellopsis sp \\
Paracalanus crassirostris F. Dahl, 1894 & \\
Pseudodiaptomus acutus F. Dahl, 1894 & Cladocera \\
Temora stylifera Dana, 1848 & Diaphanossoma brachyurum Lievin, 1848 \\
Eucalanus sewelli Dana, 1849 & Bosmonopsis deitersa Richardi, 1895 \\
& Alona sp \\
Copepoda (Cyclopoida) & Chaetognatha \\
Oithona hebes Giesbrecht, 1891 & Sagitta sp \\
Oithona oswaldocruzi L Oliveira, 1947 & \\
Hemicyclops thalassius & Appendicularia \\
Vervoorty Ramires, 1966 & Oikopleura sp \\
Caligus elongatus Nordman, 1943 & \\
Hemicyclops thalassius & Hydromedusae \\
Vervoorty Ramires, 1966 & Nematoda \\
Mesocyclops sp & Isopoda \\
Cyclops sp & Amphipoda \\
Eucyclops sp & Ostrocoda \\
Apocyclops panamensis Marsh, 1982 & \\
& MEROPLANCTON \\
Copepoda Harpaticoida & Gasrropoda (larva) \\
Euterpina acutifrons Dana, 1892 & Bivalvia (veliger) \\
Atheylla sp & Polychaeta (trocofora) \\
Ergasilus sp & Brachyura (zocas) \\
Harpaticoides sp & Cirripedia (cypris e nauplii) \\
& Copepoda (nauplii) \\
Rotifera & Porcelanidae (larva) \\
Brachionus plicatilis 0 F Muller, 1786 & Pisces (ovos e larvas) \\
Brachionus angularis Gosse, 1851 & \\
Brachionus rubens Ehrenberg, 1838 & \\
Brachionus quadridentatus Hermann, 1766 & \\
Brachionus calciflorus Pallas, 1766 & \\
Ascomorpha sp & \\
Asplarichna sp & \\
\hline
\end{tabular}

Figura 2 - Zooplâncton encontrado no estuário do Rio Bacanga / São Luis- MA( outubro de 1997 a outubro de 1998)

Tabela 1 - Distribuição de Vibrio cholerae em associação com o zooplâncton dos estuários dos rios Anil e Bacanga - São Luis / MA ( outubro de 1997 a outubro de 1998).

\begin{tabular}{|c|c|c|c|c|c|c|c|c|c|c|c|c|}
\hline \multirow[b]{3}{*}{ Ano/mês } & \multicolumn{4}{|c|}{ Vibrio cholerae não 01/não 0139} & \multicolumn{4}{|c|}{ Vibrio cholerae $01 * *$} & \multicolumn{4}{|c|}{ Vibrio cholerae 0139** } \\
\hline & \multicolumn{2}{|r|}{ Bacanga } & \multicolumn{2}{|r|}{ Anil } & \multicolumn{2}{|c|}{ Bacanga } & \multicolumn{2}{|c|}{ Anil } & \multicolumn{2}{|c|}{ Bacanga } & \multicolumn{2}{|c|}{ Anil } \\
\hline & 1 & 2 & 1 & 2 & 1 & 2 & 1 & 2 & 1 & 2 & 1 & 2 \\
\hline \multicolumn{13}{|l|}{1997} \\
\hline out & - & - & - & - & - & + & + & - & - & - & - & - \\
\hline nov & - & - & - & - & - & - & - & - & - & - & - & - \\
\hline dez & 1 (II) & - & - & 4 (I; III) & + & + & - & - & + & + & - & - \\
\hline \multicolumn{13}{|l|}{1998} \\
\hline jan & 5 (II) & - & - & - & + & + & + & + & - & - & - & + \\
\hline fev & 3 (I; II) & 2 (II) & - & - & + & + & - & - & - & + & - & - \\
\hline mar & 5 (II) & 6 (I; II) & - & 3 (II) & + & - & + & + & - & - & - & - \\
\hline$a b r$ & 8 (I; II) & 11 (I; II) & - & - & - & + & + & + & + & + & + & + \\
\hline mai & 2 (I; II) & 1 (II) & - & - & - & + & + & + & - & - & + & - \\
\hline jun & - & 2 (I; II) & - & - & + & + & + & + & + & - & - & + \\
\hline jul & - & - & - & - & + & + & + & + & - & - & - & - \\
\hline ago & - & - & - & - & + & + & + & + & - & - & + & + \\
\hline set & $2(\mathrm{I} ; \mathrm{II})$ & - & - & - & + & + & + & + & + & - & + & + \\
\hline out & - & - & - & - & - & - & - & + & + & - & - & - \\
\hline
\end{tabular}

1, 2, 3, 4, 5, 6, 8, 11 número de isolados em cada amostra; I; II; III grupos bioquímicos de Heiberg; + presença da bactéria; - ausência da bactéria ; * processo clássico de isolamento; ** imunofluorescência direta 
Vibrio cholerae 01 foi demonstrado, pela imunofluorescência direta, em 37 (71,1\%) amostras de zooplâncton, enquanto 0 V. cholerae 0139, em 17 (32,7\%). Em 12 amostras foram evidenciados os dois sorogrupos (Tabela 1 ).

Formas viáveis, mas não cultiváveis estavam presentes em 17 (70,8\%) das 24 amostras estudadas. No material corado havia tanto organismos inteiros quanto fragmentos, tendo-se constatado a associação bacteriana com os dois tipos de estrutura ( Figura 3).

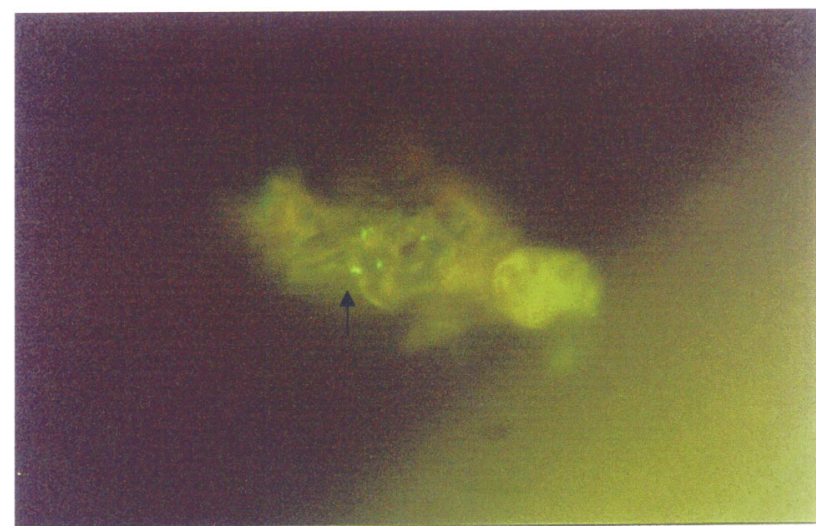

Figura 3 - Imunofluorescência direta: Vibrio cholerae $0_{1}$ em associação com organismo zooplanctônico.

A salinidade da água manteve média de 24,5 partes por mil na estação 1 e de 22,4 partes por mil na estação 2 do rio Bacanga. 0 nível mais elevado foi registrado nos meses de dezembro de $1997 \mathrm{e}$ janeiro de 1998. A partir de fevereiro, houve redução chegando a 11,5 e 12,7 partes/mil, no mês de abril, nas estações 1 e 2, respectivamente.

No rio Anil os níveis mantiveram-se acima de 30 partes por mil, exceto nos meses de setembro e outubro de 1998, quando foram registrados os valores de 23,2 e 29,7.

A temperatura da água manteve-se entre 28,1 e $31,3^{\circ} \mathrm{C}$ no estuário do Rio Bacanga e entre 27,2 e 29,8 ${ }^{\circ} \mathrm{C}$, no Rio Anil. Em ambas as áreas notou-se elevação de 2 graus durante o período chuvoso.

Com relação ao pH, houve variação de 6,5 a 9,8 no estuário do rio Bacanga e de 6,2 a 9,0 no estuário do rio Anil. Niveis superiores a 9,0 foram registrados nos meses de maio, junho e julho nas duas estações de amostragem do Rio Bacanga, enquanto no rio Anil verificou-se pH de 9,0 no mês de julho, em ambas as estações.

Coeficiente de correlação linear ( $r$ ) foi calculado entre variações dos fatores ambientais abióticos e número de de amostras positivas para V. cholerae (Tabela 2). Não foi possível o cálculo do coeficiente em relação ao V. cholerae não 01 , isolado das amostras do rio Anil, uma vez que apenas duas amostras foram positivas, enquanto todas as amostras do sorogrupo 0139 foram coletadas na mesma faixa de temperatura.

\section{DISCUSSÃ0}

0 estudo da interação de V. cholerae com zooplâncton apresenta dificuldades específicas quando realizado in situ, em decorrência da multiplicidade de fatores envolvidos no fenômeno e das freqüentes mudanças das condições ambientais em estuários. No presente estudo, duas situações distintas podem ser identificadas, levando-se em conta que os sorogrupos não 01 foram estudados no estado cultivável, enquanto os sorogrupos 01 e 0139 , no estado viável, mas não cultivável, características fisiológicas essencialmente distintas, sendo o estado não cultivável considerado forma de resistência, capaz de sobreviver em condições ambientais adversas por períodos prolongados?

0 conjunto do zooplâncton coletado demonstra a grande diversidade de grupos, compatível com a riqueza e dinâmica próprias do ambiente estuarino. A determinação do percentual de cada grupo dentro da comunidade zooplanctônica demonstrou clara predominância da classe Copepoda em 98,1\% das amostras coletadas no estuário do Rio Anil e em 86,5\% das amostras do Rio Bacanga, dados semelhantes aos encontrados anteriormente nos mesmos ambientes ${ }^{21}$.

Houve maior variedade de espécies entre os copépodes no Rio Anil, observando-se a presença de quetognatos em moderada concentração no período de janeiro a junho de 1998. № Rio Bacanga chamou a atenção a maior variedade de Rotifera e a presença de Cladocera, grupos que são mais bem adaptados a ambientes aquáticos com baixa salinidade ${ }^{27}$. Registramos que as águas do Rio Bacanga são represadas por uma barragem, sofrendo menor influência das marés, 0 que poderia estar influenciando 0 padrão de distribuição zooplanctônica nesse estuário.

A ausência de detecção do sorogrupo $01 \mathrm{de} \mathrm{V}$. cholerae pelo método clássico de cultivo está de acordo com outros pesquisadores ${ }^{7523}$. A hipótese de que a concentração de bactérias diminui no ambiente a ponto de não permitir 0 crescimento nos meios de cultura parece não se justificar, a partir da constatação de formas viáveis, mas não cultiváveis em associação com a flora e fauna aquáticas ${ }^{8}{ }^{15}$. Estudos demonstram que cada copépode pode ser colonizado por até $10^{4}$ bactérias, 0 que seria suficiente para produzir infecção em pessoas com acloridria. Durante 0 bloom de zooplâncton a proliferação de bactérias se acentua, tornando este risco ainda maior?

Os meios de enriquecimento e seletivos rotineiramnete empregados no estudo de amostras ambientais foram desenvolvidos para material clínico, de modo que as alterações metabólicas

Tabela 2 - Coeficientes de correlação linear (r) entre variação depH, salinidade etemperatura enúmero de amostras positivas para V. cholerae - São Luis/MA ( outubro de 1997 a outubro de 1998).

\begin{tabular}{|c|c|c|c|c|c|c|}
\hline \multirow{2}{*}{$\begin{array}{l}\text { Parâmetro } \\
\text { ambiental }\end{array}$} & \multicolumn{2}{|c|}{ Vibrio cholerae não 01 /não 0139* } & \multicolumn{2}{|c|}{ Vibrio cholerae $01 * *$} & \multicolumn{2}{|c|}{ Vibrio cholerae 0139** } \\
\hline & Bacanga & Anil & Bacanga & Anil & Bacanga & Anil \\
\hline$\overline{\mathrm{pH}}$ & 0,63 & - & 0,67 & 0,98 & $-0,89$ & $-0,87$ \\
\hline Salinidade & $-0,89$ & - & 0,52 & 0,54 & 0,33 & $-0,24$ \\
\hline Temperatura & 0,001 & - & 0,001 & 0,001 & 0,001 & - \\
\hline
\end{tabular}


exibidas pelas formas não cultiváveis poderiam interferir na capacidade de multiplicação e crescimneto bacteriano nos meios disponíveis ${ }^{15}$.

A imunofluorescência direta revelou V. cholerae $01 \mathrm{em} 37$ (71,1\%) das 52 amostras de zooplâncton, 0 que, aliado ao encontro das formas viáveis, mas não cultiváveis, demonstra a sobrevivência do vibrião nos estuários dos rios Anil e Bacanga. No material corado havia tanto organismos inteiros, como fragmentos, tendo sido observado a associação da bactéria, na forma viável, mas não cultivável, com os dois tipos de estrutura. A observação das lâminas não permitiu identificar qual grupo estava especificamente envolvido na associação. № entanto, a constatação do predomínio da classe Copepoda em $98,1 \%$ das amostras do rio Anil e em 86,5\%, do rio Bacanga, indica forte possibilidade da associação com estes grupos de organismos.

0 reconhecimento do fenômeno ganha maior importância ao se considerar a manutenção do potencial infeccioso da bactéria nessa condição, conforme demonstrado em trabalho experimental ${ }^{7}$. $\mathrm{A}$ adesão direta de $\mathrm{V}$. cholerae a superfícies contendo quitina favoreceria a produção de cólera, uma vez que nessa situação a bactéria está mais protegida dos efeitos do $\mathrm{pH}$ ácid $0^{26}$.

Ressalta-se, ainda, o encontro de V. cholerae 0139 em 32,7\% das amostras, uma vez que 0 surgimento deste patógeno, em 1992, despertou a necessidade de vigilância epidemiológica em relação ao seu possível envolvimento da gênese de doença diarréica semelhante à cólera clássica ${ }^{1}$.

A análise dos fatores ambientais bióticos e abióticos permitiu identificar flutuação sazonal, traduzida pela presença de organismos da classe Rotifera, pela acentuação do $\mathrm{pH}$ e da temperatura e pela diminuição da salinidadeno estuário do rio Bacanga durante a estação chuvosa. No rio Anil este comportamento foi observado de forma menos definida, pela presença de quetognatos em concentração moderada na estação 2 e pelas elevações de pH e temperatura registradas no período chuvoso, mantendo-se a salinidade em valores elevados. Acomparação desteúltimo parâmetro entre os dois estuários mostra níveis mais baixos no rio Bacanga em todos os meses, 0 que pode ser explicado pela presença de uma Barragem, cujas comportas são abertas a intervalos trimestrais.

A distribuição das 14 amostras de zooplâncton das quais foram obtidos os isolados de V. cholerae não 01 mostrou que 12 (85,7\%) foram oriundas do estuário do rio Bacanga. Destas, 10 foram coletads no período das chuvas, coincidindo com as variações dos fatores ambientais e da composição zooplanctônica, 0 que caracteriza 0 padrão sazonal de distribuição de $\mathrm{V}$. cholerae neste estuário.

Asalinidade parece ter exercido a maior influência no isolamento bacteriano, considerando-se a acentuada diminuição de seus níveis no mesmo período de obtenção das amostras positivas. 0 coeficiente de correlação de - 0,89 indica que à medida que os níveis de salinidade diminuíram, maior número de amostras positivas foram detectadas. Esta observação foi reforçada pela obtenção de isolados bacterianos a partir de apenas duas amostras de zooplâncton dentre as 26 provenientes do estuário do rio Anil, onde a salinidade mantevese (exceto por dois meses) acima de 30 partes por mil.

0 coeficiente de correlação de 0,63 observado em relação ao pH mostrou que a alcalinidade do meio também favoreceu o isolamento bacteriano, embora esta correlação seja menosintensa.Jáas discretas variações da temperatura da água não exerceram influência na presença da bactéria $(\mathrm{r}=0,001)$.

Flutuação sazonal definida não foi observada em relação ao sorogrupo 01 que foi demonstrado pela imunofluorescência direta em associação com 0 zooplâcton em, pelo menos, uma estação de amostragem durante todo o período de estudo. Este padrão se repetiu com 0 sorogrupo 0139, cuja distribuição, embora não tenha sido tão uniforme quanto o V. cholerae 01, também não se relacionou às condições climáticas. Aanálise dos fatores ambientais demonstra correlação positiva moderada no rio Bacanga $(\mathrm{r}=0,67)$ e muito acentuada no rio Anil $(r=0,98)$ entre variações de $\mathrm{pH}$ e encontro do vibrião nas amostras de zooplâncton. Os coeficientes de correlação entre variações da salinidade mostraram pouca influência deste fator na associação do sorogrupo $01 \mathrm{e}$ zooplâncton. Da mesma forma, não houve correlação significativa entre detecção de V. cholerae 01 e temperatura.

\section{REFERÊNCIAS BIBLIOGRÁFICAS}

1. Albert MJ. Personal reflections on discovery of Vibrio cholerae 0139 synonym Bengal: a tribute to team work and international collaboration. Journal of Diarrhoeal Disease Research 11: 207-210, 1993.

2. Araújo DB, Martins SCS, Albuquerque LMB, Hofer E. Influence of copepod Mesocyclops longisectus (Crustaceae Cyclopidae) on the survival of Vibrio cholerae 01 in fresh water. Cadernos de Saúde Pública 12: 551-554, 1996.

3. Bjornberg TKS. On marine free-living copepods of Brazil. Boletim do Instituto de Oceanografia (USP) 13: 3-142, 1963.

4. Boltovskoy D. ed. Atlas del zooplancton del Atlantico Sudoccidental e metodos de trabajo com el zooplancton marino. Mar del Plata. Instituto Nacional Investigación y Desarrollo Pesquero, 1981.

5. Brandorff GO, Koste W, SmirnovNN. The composition and structure of Rotiferan and Crustacean communities of the Lower Rio Nhamundá, Amazonas, Brazil. Studies of Neotropical Fauna and Environment 17: 69-121, 1982.

6. Brayton PR, Colwell RR. Fluorescent antibody staining method for enumeration of viable environmental Vibrio cholerae 01. Journal of Microbiological Methods 6: 309-314, 1987.

7. Colwell RR. Global climate and infectious disease: the cholera paradigm. Science 274: 2025-2031, 1996.

8. Colwell RR, Brayton, PR, Grimes DJ, Roszak DB, Huq AS, Palmer LM. Viable but nonculturable Vibrio cholerae and related pathogens in the environment: implications for release of genetically engineered microorganisms. Biotechnology 3: 817-820, 1985.

9. Feachem RG. Environmental aspects of cholera epidemiology - I. A review of selected reports of endemics and epidemic situations during 1961-1980. Tropical Disease Bulletin 78: 675-698, 1981.

10. Fundação Instituto Brasileiro de Geografia e Estatística (IBGE) . Atlas do Estado do Maranhão. Rio de Janeiro, 1984.

11. Hasan JAK, Berstein D, Huq A, Loomis L, Tamplin ML, Colwell RR. Cholera DFA: an improved direct fluorescent monoclonal antibody staining kit for rapid detection and enumeration of Vibrio cholerae 01. FEMS Microbiology Letters 120: 143-148, 1994.

12. Hasan JAK, Huq A, Nair B, Garg S, Mukhopadhyay AK, Loomis L, Berstein D, Colwell RR. Development and testing of monoclonal antibody based rapid immunodiagnostic test kits direct detection of Vibrio cholerae 0139 synonym Bengal. Journal of Clinical Microbiology 33: 2935-2939, 1995.

13. Heiberg B. The biochemical reactions of vibrios. Journal of Hygiene 36: 114-117, 1936. 
14. Hofer E, Ernandez D. Incidência de Vibrio cholerae não 01 em afluentes de estações de tratamento de esgotos da cidade do Rio de Janeiro. Revista de Microbiologia 21: 31-40, 1990.

15. Huq A, Small EB, West PA, Huq MI, Rahman R, Colwell RR. Ecological relationship between Vibrio cholerae and planktonic crustacean copepods. Applied and Environmental Microbiology 45: 275-283, 1983.

16. Huq A, West P, Small EB, Huq MI, Colwell RR. Influence of water temperature, salinity and $\mathrm{pH}$ on survival and growth of toxigenic Vibrio cholerae serovar 01 associated with live copepods in laboratory microcosms. Applied and Environmental Microbiology 48: 420-424, 1984.

17. Islam MS, Drasar BS, Bradley DJ. Attachment of toxigenic Vibrio cholerae 01 to various freshwater plants and survival with a filamentous green alga, Rhizocloniun fontanum. Journal of Tropical Medicine and Hygiene 92: 396-401, 1989.

18. Islam MS, Drasar BS, Bradley DJ. Long-term persistence of toxigenic Vibrio cholerae 01 in the mucilagenous sheath of a blue-green alga Anabaena variabilis. Journal of Tropical Medicine and Hygiene 93: 133-139, 1990.

19. Islam MS, Drasar BS, Sack B. The aquatic environment as a reservoir of Vibrio cholerae: a review. Journal of Diarrhoeal Disease Research 11: 197-206, 1993.

20. Koch R. An adress on cholera and its bacillus. British Medical Journal 2: 403-407, 1884.

21. Lopes MJS. Zooplâncton do estuário do rio Anil. São Luis - MA. Boletim do Laboratório de Hidrobiologia (Universidade Federal do Maranhão) 4: 77-96, 1982.

22. Martins MT, Pessoa GVA, Sanchez PS, Sato MIZ, Coimbrão CA, Monteiro CK, Marques E. Ocurrence of V. cholerae 01 non toxigenic in wastewater from São Paulo, Brazil. Water Science and Technology 24: 363-366, 1991.

23. Martins MT, Sanchez PS, Sato MIZ, Brayton PR, Colwell RR. Detection of Vibrio cholerae 01 in the aquatic environment in Brazil employing direct immunofluorescence microscopy. World Journal of Microbiology and Biotechnology 9: 390-392, 1993.

24. Miller CJ, Drasar BS, Feachem RG. Response of toxigenic Vibrio cholerae 01 to physico-chemical stresses in aquatic environment. Journal of Hygiene 93: 475-496, 1984.

25. Miller CJ, Feachem RG, Drasar BS. Cholera epidemiology in developed and developing countries: new thoughts on transmission, seasonality and control. Lancet 2: 261-263, 1985.

26. Nalim DR, Daya V, Reid A, Levine MM, Cisneros L. Adsorption and growth of Vibrio cholerae on chitin. Infection and Immunity 25: 768-770, 1979.

27. Oliver SR. Los Cladoceros Argentinos. Revista del Museo de la Plata. Sección zoologia 7: 173-269, 1962.

28. Patel M, Isaacson M, Gouws, E. effect of iron and $\mathrm{pH}$ on the survival of Vibrio cholerae in water. Transactions Royal Society of Tropical Medicine and Hygiene 89: 175-177, 1995.

29. Pollitzer R. Cholera. Monograph 43. World Health Organization, Geneva, Switzerland, 1959.

30. Reid JW. Chave de identificação e lista de referências bibliográficas para espécies continentais sulamericanas de vida livre da Ordem Cyclopoida (Crustacea, Copepoda). Boletim de Zoologia (Universidade de São Paulo) 9: 17-143, 1985.

31. Singleton FL, Attwel RW, Jangi MS, Colwell RR. Effects of temperature and salinity on Vibrio cholerae growth. Applied and Environmental Microbiology 44: 1047-1058, 1982.

32. Sochard MR, Wilson DF, Austin B, Colwell RR. Bacteria associated with the surface and gut of marine copepods. Applied and Environmental Microbiology 37: 750-759, 1979.

33. Xu HS, Roberts NC, Adams LB, West PA, Siebeling RJ, Huq A, Huq MI, Rahman R, Colwell RR. An indirect fluorescent antibody staining procedure for detection of Vibrio cholerae serovar 01 cells in aquatic environmental samples. Journal of Microbiological Methods 2: 221-231, 1984. 